\title{
The pH Studies of Recombinant Acetohyd roxy Acid Synthase from Tobacco
}

\author{
Jung-Do Choi, ${ }^{\dagger}$ Bok-Hwan Kim, ${ }^{\ddagger}$ and Moon-Young Yoon ${ }^{\star}$ \\ Department of ('hemisty. Hanyang Liversin, Seou 133-791, Norea \\ tSchool of life Sciences, ('hinght Hationd thiversity, ('heongh 361-763, Korea \\ 'Department of Health Science, Korea Aational Open Liversity, Seoul 110-791, Norea \\ Received Febnav' 12, 2003
}

\begin{abstract}
The pll dependence of the kinetic parameters of recombinant acetolydroxy acid synthase catalyzed reaction was determined in order to obtain information about the chemical mechanism, particularly acid-base chemistry. The maxinum velocity and $V / K$ for pyruvate were bell-shaped with estimated $p K$ values of $6.5-6.7$ and 8.6 8.9, respectively. The maximun velocity and $V / K$ for 2 -ketobutyrate were also bell-shaped witl estimated pK values of $6.6-7.0$ and $8.4-8.6$. The pll dependence of $1 / \mathrm{Ki}$ for 3 -bromopyruvate, a competitive inhibitor of prruvate, was also bell-shaped, giving $\mathrm{pK}$ values almost identical with those obtained for pyruvate since the

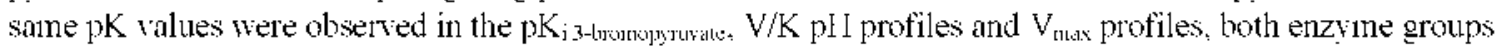
must be in their optimum protonation state for efficient binding of reactants. These results reflect that two enzime groups ate necessary for binding of substrate and/or catalysis.
\end{abstract}

Key Words : Acctohydroxy acid synthase, $\mathrm{pH}$ study, Tobacco

\section{Introduction}

Acetohydroxy acid synthase (AHAS. EC 4.1.3.18 also referred to as acetolactate synthase) catalyzes the initial common step in the biosynthesis of the branched-chain amino acids: valine. leucine. and isoleucine in plant and microorganisms. AHAS catalyzes the condensation of two molecules of py nuate to form acetolactate in the biosynthesis of valine and leucine, or the condensation of pyruvate and 2-ketobutyrate to form 2-aceto-2-hydroxybuty rate in the biosynthesis of isoleucine (Scheme l).

AHAS. which catalyzes the decarbosylation of 2-ketoacids, requires thiamine diphosphate (ThDP) and a divalent metal ion as cofactors (that anchors ThDP in the active site). AHAS also requires FAD, which is unexpected, because the reaction inclves no oxidation or reduction. ${ }^{1,2}$ The first two cofactors. ThDP and metal ion. are typical for enzy mes that catalyze the decarbosy lation of 2-ketoacids, as occurs in the first stage of the AHAS reaction. The requirement for $\mathrm{FAD}$ is unprecedented, and has also been described for glyoxylate carboligase. ${ }^{3}$ which is structurally related to AHAS, as well as the umrelated enzyme chorismate synthase. ${ }^{+}$Much interest in AHAS was stimulated by the discovery that it is the target site of at least four structurally diverse families of herbicides; sulfonylureas. imidazolinones, triazolopyrimidines. and pyrimidinyl oxybenzoates.'- These compounds bear no resemblance to 2-ketoacids and are not competitive inhibitors, suggesting that they do not bind at the active site. The structure and natural role of this herbicide-binding site is unknown.

AHAS has been studied in steady state kinetic experiments in which the rates of formation of acetolactate (AL)<smiles>CC(=O)C(=O)[O-]</smiles>

pyruvate<smiles>CC(=O)C(=O)[O-]</smiles>

pyruvate



pyruvate<smiles>CCC(=O)C(=O)[O-]</smiles>

2-ketobutyrate<smiles>CC(=O)C(C)(O)C(=O)[O-]</smiles>

2-Acetolactate

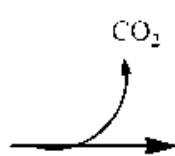

2-aceto-2-hydroxybutyrate

Scheme 1

*lo whom correspondence should be addressed. Tel: +82-2-2290-09-46: lax: +82-2-2299-0762: c-mail: my yomiahanyang.ac.kr 
and acetoly droxybutyrate (AHB) have been detemined simutaneously: The ratio between the rates of production of the two alternative products and the concentrations of the substrates py nuwate and 2-ketobutyrate leads them to $\mathrm{V}_{\mathrm{AnI}} /$ $V_{*+\perp}=R$ ([2-ketobutyrate]/[pyruvate]). Among the three enterobacterial enzymes, only AHAS 1 has a relatively low $\mathrm{R}$ factor of 2. However. AHAS II and lll have high R-values of 65 and to. respectively; suggesting a high specificity for acetohydroxybutyrate formation. This is consistent with the fact that the intracellular concentration of the major metabolic intermediate pyruvate is ligher than that of 2-ketobuty rate. indicating that the mechanism involves an irreversible and rate-deternining reaction of pyruvate. Lee et al. ${ }^{i}$ carried out steady-state kinetic studies of recombinant tobacco AHAS using pyrurate and 2-ketobutyrate as substrates. They proposed that recombinant tobacco AHAS catalyzes the reaction in the manner of a Uni Uni Ping Pong Bi Bi mechanism.

The crystallization of cataly tic subunit and AHAS enzyme ${ }^{*}$ from yeast was recently reported at $2.6 \mathrm{~A}$ resolution. This structure revealed the location of several active site features. including the position and confonmation of the cofactors ThDP. $\mathrm{Mg}^{2}$ and FAD. The structure, in combination with molecular modeling. also suggests the geometry and location of the binding site for the imidazolinone herbicide imazapyr (2-(4-isopropy 1-t-methyl-5-oxo-2-imidazolin-2y) nicotinic acid). Although an abundance of information is arailable on many aspects of the acetohydroxy acid synthase reaction. ${ }^{15.16,1^{7}}$ little is known of the chemical mechanism. This study presents an investigation of the $\mathrm{pH}$ dependence on the steady state kinetic parameters of recombinant AHAS from tobacco. Data will be discussed in terms of the reaction mechanism. particularly the acid-base chemistry:

\section{Materials and Methods}

Materials. Thimine diphosphate. GSH. FAD, $\alpha$-naphtol and creatine were obtained from Sigma Chemical Co. (St. Louis. USA). Epoxy-activated Sepharose 6B was obtained from Pharmacia Biotech (Uppsala, Sweden). All other chemicals were obtained from commercial sources and were of the highest quality available.

Enzyme Purification. Expression and purification of the recombinant acetohydroxyacid synthase was performed with a modification of the procedure described by Chang et $a$. (1997). ${ }^{\circ}$ E. coli $\mathrm{DH} 5 \alpha$ cells containing the expression vector pGEX-ALS were grown at $37^{\circ} \mathrm{C}$ in Luria-Bertani (LB) medium containing $50 \mu \mathrm{g} / \mathrm{mL}$ ampicilin to an $\mathrm{OD}_{\mathrm{fixi}}$ of 0.7 0.8. Expression of the ALS gene was induced by adding 1.0 $\mathrm{mM}$ isopropyl-D-thiogalactoside (IPTG). Cells were grown for an additional + hours at $30^{\circ} \mathrm{C}$. and harested by centrifugation at $6000 \mathrm{mpm}$ for $15 \mathrm{~min}$. The cell pellet was resuspended in PBST buffer $(150 \mathrm{mM}$ Tris- $\mathrm{HCl}$. pH 7.5. I $\mathrm{mM}$ pyruvate. $10 \%(\mathrm{v} / \mathrm{v})$ ethy lene glycol. $10 \mathrm{mM} \mathrm{MgCl}$ ) containing protease inhibitors ( $2 \mu \mathrm{g} / \mathrm{mL}$ Leupeptin $+\mu \mathrm{g} / \mathrm{mL}$ Aprotinin. $2 \mu \mathrm{g} / \mathrm{mL}$ Pepstatin A). The cell suspension was lysed by sonication at + " $\mathrm{C}$ and the homogenate was centrifuged at $20.000 \mathrm{pm}$ for $20 \mathrm{~min}$. The supernatant was applied to a GSH-coupled Sepharose $6 \mathrm{~B}$ column and unbound proteins were removed by extensive washing with the PBST buffer. GST-AHAS fusion protein was eluted from the column with an elution buffer $(50 \mathrm{mLM}$ Tris- $\mathrm{HCl}, \mathrm{pH} 8.0$. $20 \mathrm{mM} \mathrm{GSH} .10 \%(\mathrm{v} / \mathrm{v})$ etlyylene glycol $)$. The isolated protein was analyzed by SDS-PAGE and the protein concentration was detemined by the method of Bradford.

Enzyme Assay. Enzyme activities of the purified AHAS were measured according to the method of Westerfeld ${ }^{1 / 1}$ with a modification as reported previously." The standard reaction mixture contained $100 \mathrm{mM}$ potassium phosphate buffer (pH 7.5), $1 \mathrm{mM} \mathrm{ThDP}, 10 \mathrm{mM} \mathrm{MgCl}=20 \mu \mathrm{M}$ FAD. $75 \mathrm{mM}$ pyruvate. $30 \mathrm{mM} 2$-ketobuty rate and the enzyme (0.1U) in the absence or presence of various concentrations of inhibitors. Assays were initiated by the addition of AHAS and incubated at $377^{\circ} \mathrm{C}$ for $30 \mathrm{~min}$. and terminated by the addition of $6 \mathrm{~N} \mathrm{H}_{2} \mathrm{SO}_{1}$. The reaction product. acetohydroxy acid. was allowed to decarboxy late at $60^{\circ} \mathrm{C}$ for $15 \mathrm{~min}$. The acetoin fomed by acidification was incubated and colorized with $0.5 \%$ creatine and $5 \% \alpha$-naphthol at $60{ }^{\circ} \mathrm{C}$ for $15 \mathrm{~min}$. All data were collected using a Shimazu spectrophotometer. The temperature was maintained at $37^{\circ} \mathrm{C}$ using a circulating water bath with the capacity to heat and cool the thermo spacers in the cell compartment. All reactions were carried out in a 1-mL cuvette with I-light path. The absorbance of the reaction mixture was detemined at $525 \mathrm{~nm}$. One unit (U) of activity was defined as the amount of enzyme required to form $1 \mu$ mol of acetolydrosy acid per munute under the assay conditions described above. Specific activities of AHAS were expressed as units (U) per mg of protein.

pH Studies. To be certain that the kinetic mechanism is $\mathrm{pH}$ independent and to estimate the $\mathrm{K}_{\mathrm{NI}}$ values for pyruvate and 2-ketobutyrate. steady-state kinetic pattems in the absence of products were obtained at $\mathrm{pH} 6.0,7.5$ and 9.0. It was obtained by measuring the rate at different levels of pyrurate and several fixed levels of 2-ketobutr rate and at saturating concentration of cofactors. Once the measured kinetic patterns were shown to be $\mathrm{pH}$ independent, saturation curves for pyruvate and 2-ketobuty rate were obtained at a fixed saturating concentration of the cofactors as a function of $\mathrm{pH}$. Buffers used at $100 \mathrm{mM}$ concentration were MES at 5.5 to 6.5 . MOPS at pH 6.5 to 8.0 and TAPS at pH 8.0 to 9.5 . All buffers were titrated to the appropriate $\mathrm{pH}$ with $\mathrm{KOH}$. Several of the assalys were repeated at a given $\mathrm{pH}$ using different buffers to eliminate the possibility of activation by the buffers. At the pH extremes. the concentration of cofactors was doubled in a separate assay to saturate. No significant rate change was detected. Inhibition data were obtained for 3-bromopy nuvate, competitive inhibitor versus pynuvate. The pyruvate concentration varied. while the 2ketobuty rate concentrations were maintained at saturation. Once the competitive nature of the inhibition was determined to be $\mathrm{pH}$ independent. Dixon experiments were performed in which the variable substrate was fixed at a concentration equal to its $K_{m}$. and the inhibitor concentration was varied from zero over the range where there was inhibition. 3- 
bromopyruvate was unstable and precipitated above ligher $\mathrm{pH}(>8.0)$.

Data analysis. Reciprocal values of the steady state rate were plotted as a function of the reciprocal of the substrate concentrations. Data were analyzed according to the appropriate rate equations of Cleland (1979) ${ }^{12}$ Individual saturation curve were fit to Eq. (1). Data for the sequential kinetic patterns were fit using Eq. (2). Competitive inhibition data at each $\mathrm{pH}$ were fitted to Eq. (3). Data for $\mathrm{pH}$ profile that decreased with a slope of -1 at low $\mathrm{pH}$ and a slope of -1 at high $\mathrm{pH}$ were fit to $\mathrm{Eq}(4)$.

$$
\begin{aligned}
& v=V A /(K+A) \\
& v=V A B /\left(K_{14} K_{b}+K_{a} B+K_{l} A+A B\right) \\
& v=V A /\left\{K\left(1+I / K_{1:}\right)+A\right\} \\
& L \log y=\log \left\{C /\left(1+\left[H^{\prime}\right] / K_{l}+K_{J} /[H]\right)\right\}
\end{aligned}
$$

In Eqs. (1) and (2). $A$ is the reactant concentration. $V$ is the maximum velocity. and $\mathrm{K}$ is the Michaclis constant for the varicd substratc. In Eq. (3). I is inllibitor concentration and $\mathrm{K}_{\mathrm{s}}$ is inlibition constant for slope. In $\mathrm{Eq}(4) . \mathrm{H}$ is the lyddrogen ion concentration. $\mathrm{K}_{1}$ and $\mathrm{K}_{2}$ represent dissociation constant for enty me groups. $\mathrm{y}$ is $\mathrm{V} / \mathrm{K}$. and $\mathrm{C}$ is the $\mathrm{pH}-$ independent value of $\mathrm{y}$.

\section{Results and Discussion}

It is important to determine the stability of an enty me over the $\mathrm{pH}$ range studied. since this could poicntially give rise to incorrectly deternined values of the kinetic parameiers as well as the inlibition constants for inlubitors. In this study. acctolydroxy acid synthase was incubated with the buffer systems for up $10.30 \mathrm{~min}$. Aliquots were removed at various time points and assayed for activily at $\mathrm{pH} 7,5$, a $\mathrm{pH}$ where



Figure 1. Initial velocity patiens for the acclohydroxy acid synthase at $\mathrm{pI}$ 9.0. The assays were carred out under standard conditions. The fesults fitted plots ( $\mathbf{\nabla}$ ) for $0.5 \mathrm{mM}_{3}$ ( ) for $2 \mathrm{mM}$, ( ) for $7 \mathrm{mM}$, ( $\mathbf{a}$ ) for $40 \mathrm{~mm}$ of 2 -ketobutrate, respectively: Points are experimental and the solid lines are from a lit using

\begin{tabular}{|c|c|c|c|}
\hline Parameters & Variable Substrate & $\mathrm{PK}_{\mathrm{J}} \pm \mathrm{Sli}$ & $\mathrm{pK}_{2} \pm \mathrm{SH}$ \\
\hline$V_{\text {rrial }}$ & pyrutate & $6.5 \pm 0.1$ & $8.6 \pm 0.1$ \\
\hline$V_{\text {rriat }}$ & 2-ketobuty rate & $7.0 \pm 0.1$ & $8.4 \pm 0.2$ \\
\hline $\mathrm{V} \mathrm{K} \mathrm{K}_{\text {pringale }}$ & pyrupate & $6.7 \pm 0.2$ & $8.9 \pm 0.1$ \\
\hline $\mathrm{V} \mathrm{K}$-ketutuly sate & 2-ketobut rate & $6.6 \pm 0.1$ & $86 \pm 0.1$ \\
\hline $\mathrm{pK}_{\mathrm{t}}^{\mathrm{c}}$ & pyrusate & $6.5 \pm 0.2$ & $8.9 \pm 0.2$ \\
\hline
\end{tabular}
equation (1).
Table 1. Summery of pK wallus obtained from the pl I dependence of kinetic parameters"

" $\mathrm{pK}_{1}$ indicates that the gmup must be protonated for enzyme activity and $\mathrm{pK}_{2}$ indicated that the group must be deprotonated. "Substrate indicated was varied around $\mathrm{K}_{\mathrm{mL}}$ and another subsirale was salurated. " $p \mathrm{~K}_{\mathrm{l}}$ was obtained using only provale substrate.

the enzyme is known to be stable. "No significant decrease in activity occurred at the $\mathrm{pH}$ extremes $(\mathrm{pH} 5.5$ and $\mathrm{pH} 9.0)$ (data not shown). An estimate of the variation of kinetic mechanism over the $\mathrm{pH}$ range to be studied is required in order to ensure that enzy me complex is being titrated. Thus. steady state kinetic patterns were obtained at $\mathrm{pH} 5.5$ and 9.0 by varying 2-ketobutyrate at fixed level of pyruvate. The results at $\mathrm{pH} 7.5$ are shown in Figure 1. These results are in agreement with the ping pong mechanism of pyruvate prior to 2-ketobuty rate noted by Lee $e t a l$.

The $\mathrm{pH}$ dependence of the kinetic parameters for acetohydroxy acid synthase was detemined over the $\mathrm{pH}$ range 5.5 to 9.5 in the presence of both substrates pyruvate and 2ketobuty rate. Each $\mathrm{pH}$ profile provides information concerning the ionizable groups of the enzyme and its substrates as well as information about binding and catalysis. A pH dependent decrease in $V / K$ or $V_{\text {mat }}$ profiles provide information regarding ionizable groups on substrates and/or the enzyme that must be in a given state of ionization to participate in either catalysis or binding. ${ }^{1.3}$ Interpretation of these profiles requires the assumption that there is only one ionization state of active site residues that supports catalysis. and that all protonation/deprotonation equilibria are rapid. The observed $\mathrm{pK}$ values from each of the $\mathrm{pH}$ profiles generated are summarized in Table 1 .

The $\mathrm{V} / \mathrm{K}$ for a reactant is the second-order rate constant for conversion of free enzyme and free reactant to products. Thus, the $\mathrm{pKs}$ observed in the $\mathrm{V} / \mathrm{K} \mathrm{pH}$ profiles for pyruvate reflect acid-dissociable functional groups in E:2-ketobutyrate:ThDP:FAD:Mg. The pKs observed in the $\mathrm{V} / \mathrm{K}$ pH profiles for 2-ketobuty rate reflect acid dissociable functional groups in E:py ruvate:ThDP:FAD:Mg. The $\mathrm{V} / \mathrm{K}$ profiles for pynuvate and 2-ketobutyrate on either the acidic or the basic side decrease to a limiting slope of one. indicating that a change in the ionization state of a single group on each side of the profile is involved in the loss of activity. The $\mathrm{V} / \mathrm{K}$ profiles for pyruvate and 2-ketobutyrate have the same maximum value at $\mathrm{pH} 7.5$ and decrease on either side of this maximum (Figure 2B and 3B, respectively). However. the basic side of the $\mathrm{V} / \mathrm{K}$ for prruvate decreased slightly. The same activity observed near neutral $\mathrm{pH}$ in the $\mathrm{V} / \mathrm{K}$ profiles might be related to no change in the substrate requirement of AHAS. The $\mathrm{pK}$ values for $\mathrm{V} / \mathrm{K}_{\text {pyyurare }}$ profile obtained on the acidic side are 6.4 , while that on the basic side is 9.0 . The $\mathrm{pK}$ 

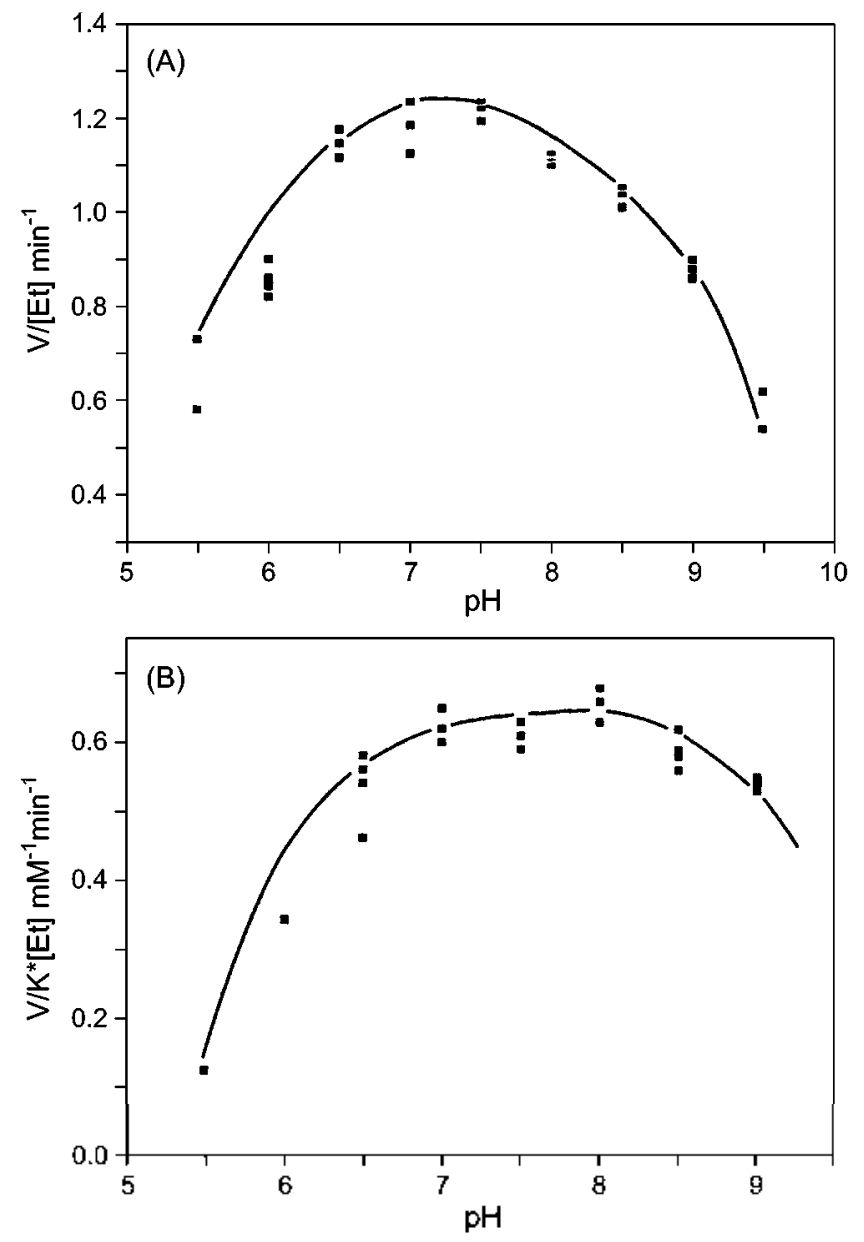

Figure 2. pll dependence of $\mathrm{V}_{\text {rmax }}(\mathrm{A})$ and $\mathrm{V} / \mathrm{K}$ (B) ol pyruvale in the AlLAS reaction. 'lhe concentration of pyruvate was varied around its $K_{111}$ with 2-ketobutstate concentration maintained at saturation. The points are expetimental values. The curves for $\mathrm{V}_{\text {minax }}$

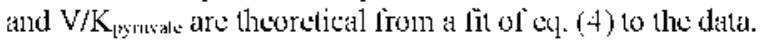

values for $\mathrm{V} / \mathrm{K}_{\text {--kitututy ratc }}$ profile are 6.4 on the acidic side and 8.4 on the basic side. The observed pK values from V/

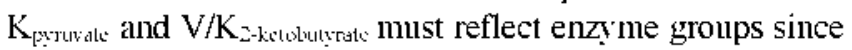
py ruxate and 2-ketobuty rate exhibit no $\mathrm{pKs}$ in the $\mathrm{pH}$ range 5.5-9.5. Qualitatively similar $\mathrm{pH}$ profiles are observed in the $\mathrm{V} / \mathrm{K}$ profiles of pynusate and 2-ketobuty rate. No change in the value of the acidic pKs was observed. However, there is an apparent perturbation in the value of the basic $\mathrm{pK}$ from 8.4 to 9.0 . The bell-shaped nature of the $\mathrm{pH}$ rate profiles obtained for pyruvate and 2-ketobuty rate suggests that two groups on AHAS are responsible for the observed pKs function in catalysis. These groups are also required in their correct protonation state for the binding of 3-bromopy ruvate since its dissociation constant increases above and below the same pKs observed in the $\mathrm{V} / \mathrm{K}$ profiles (vide infra).

The $V_{\text {max }}$ profile contains information about the ionization states of the central enzyme-substrate complexes. The $\mathrm{V}_{\max }$ profiles show that substrate behaves similarly between the py ruvate and 2-ketobuty rate. The maximum velocity obtained under pyruvate concentrations and saturating 2-ketobutyrate decreased at low and high $\mathrm{pH}$ with $\mathrm{pK}$ values of 6.3 and 8.9 .
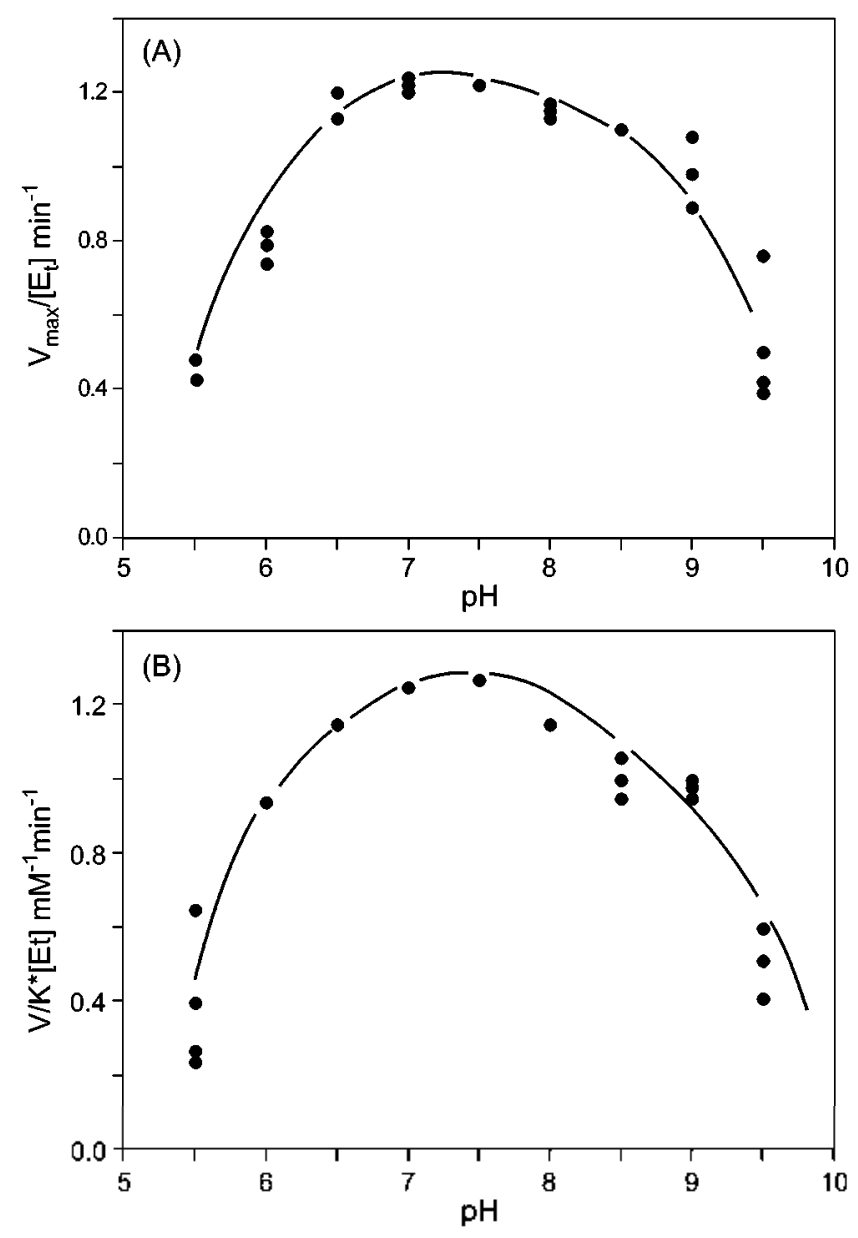

Figure 3. $p H$ dependence of $V_{\text {thax }}(A)$ and $V / K(B)$ of $2-$ ketobulyrate in the ALLAS reaction. The concentration of 2ketobulyrate was varied around its $\mathrm{K}_{\mathrm{m}}$ with pynvate concentration maintained at saturation. The points are experimental values. The curves for $V_{\max }$ and $V / K_{2}$-ketsburyare are theoretical from a tit of eq. (4) to the data.

respectively (Figure $2 \mathrm{~A}$ ). The maximum velocity for 2ketobuty rate decreased at low and high $\mathrm{pH}$ with $\mathrm{pK}$ values of 6.5 and 8.7. respectively (Figure 3A). The maximum velocity profiles have an optimum at $\mathrm{pH} 7.5$ under conditions pyruvate varying at saturating 2 -ketobuty rate and 2-ketobutyrate varying at saturating pynuate. A comparison of the maximum velocity of py ruvate and 2-ketobuty rate shows the binding of pynivate and 2-ketobuty rate to the enzyme does not affect the ionization of the group on the both side of the $\mathrm{pH}$ profiles since nearly the same $\mathrm{pK}$ (approximate $6.3-6.5$ on the acidic side and approximate 8.7-8.9 on the basic side) value was observed within error limits. The two groups likely function in catalysis as discussed above for $\mathrm{V} / \mathrm{K}$ profiles. The group with a $\mathrm{pK}$ of $6.3-6.5$ is required to be unprotonated for optimal activity and is responsible for a $\mathrm{pH}$ dependent activation. as it becomes unprotonated. The $\mathrm{pK}$ values of the acidic side (6.3-6.5) were similar to those observed in the $\mathrm{V} / \mathrm{K}$ profiles. indicating that there was no perturbation as the $\mathrm{pH}$ increased from 5.5 to 7.5 . The $\mathrm{pK}$ values of the basic side (8.7-8.9) were slightly different from those observed in the $\mathrm{V} / \mathrm{K}$ profiles. indicating that there was some perturbation as 


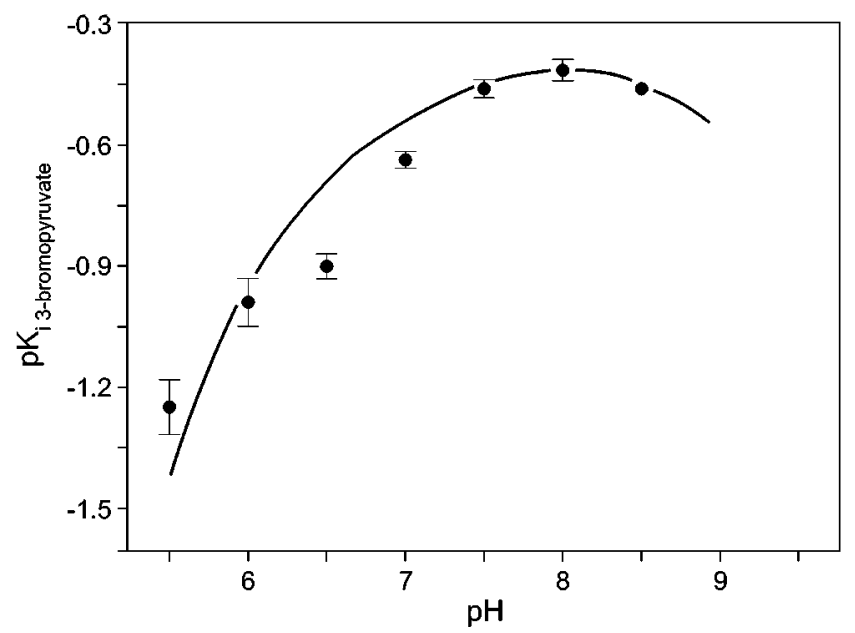

Figure 4. pll dependence of 3-bromopyruvale binding to AHAS. All dala were obtained from Ibixon plots varying the concentration of 3-bromopyruvate and pyruate equal to its $\mathrm{K}_{\mathrm{m}}$. Data were obtained as discussed under Methods and Materials. The data were filled to eq. (4).

the pll increased from 7.5 to 9.5 . Both groups observed in the $V_{\max }$ proliles were observed in the $\mathrm{V} / \mathrm{K}$ proliles, suggesting that these groups interact with pyruvate and 2ketobutyrate, which are bound sequentially to the enzyme."

In order to luther test if the pK values obtained from the $\mathrm{pH}$ dependence of kinetic parameters are intrinsic, the pII dependence of the $K_{i}$ for 3-bromopyruvate, a structural analogue (3-hydrogen of pyruvate replaced by brome) and competitive inhibitor of pyruvate, was determined. Since this inhibition is competitive it is only observed under limited substrate conditions and where all steps prior to addition of substrate have come to thermodynamic equilibrium. Therefore, true $\mathrm{pK}$ values observed for the $\mathrm{pl}$ l dependence of $\mathrm{K}_{\mathrm{i}}$ values for competitive inhibitors can be used to check whether or not the observed $\mathrm{pK}$ values in the substrate profile and true $\mathrm{pK}$ values if the protonation state of these groups affects inhibitor binding. ${ }^{14}$ The $\mathrm{pK}_{\mathrm{i}}$ of 3-bromopyruvale was unstable at high $\mathrm{pH}$, but decreased slightly above pH 7.5. These data were fitted to the bell-shaped pH profiles in which the limiting slopes were $-I$ and $-I$. The observed $p \mathrm{~K}_{i}$ values for 3-bromopyruvate were 6.5 on the acidic side and 8.9 on the basic side (Figure 4). The pK values obtained from the $\mathrm{pK}_{i}$ prolite of 3-bromopyruvate are essentially the same as the values observed from the $\mathrm{V} / \mathrm{K}$ profiles of pyruvate and 2-ketobutyrate. Thus, the observed $\mathrm{pK}$ values in the V/K profiles of pyruvate and 2-ketobutyrate are indeed intrinsic.

The pKs values observed at pH 8.4 and 9.0 on the basic side in the V/K profile of $\Lambda \mathrm{H} \Lambda \mathrm{S}$ activity were also seen in the $\mathrm{pK}_{\mathrm{i}}$ profile with 3-bromopyruvate as competitive inhibitor against pyruvate. Since there are no common inhibitor or substrate $\mathrm{pK}$ values in this $\mathrm{pH}$ range, this decrease on the basic side in the $\mathrm{pK}_{i}$ profile indicates a loss of binding of this inhibitor as a result of ionization of a group on the enzyme. The pKs values seen on the acidic side of the $\mathrm{V} / \mathrm{K}$ prolite at pH I 6.4, in either the presence of pyruvate or 2-ketobutyrate,

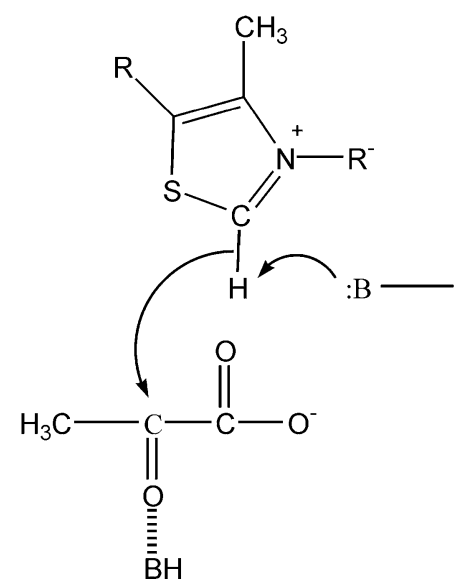

Scheme 2, Proposed acid-base chemical mechanism of AIIAS.

and the $\mathrm{pK}_{\mathrm{i}}$ seen on the acidie side of 3-bromopyruvate also indicate the ionization of a group on the enzyme.

$\Lambda$ mechanism taking into account the above pH sludies is shown in Scheme 2. Pyruvate binds 10 enzyme as the monoanion with a carboxyl group. $\Lambda$ proton is abstracted from $\mathrm{C}-2$ by an enzyme general base with a pl of 6.3-6.5. The $\mathrm{pK}$ for general base is observed in all of the $\mathrm{V}$ profiles, all of the $V / K$ profiles, and the $\mathrm{pK}_{\mathrm{i}}$ s-bremopyruate prolile. Considering the conventional view of the catalytic cycle, ThDP ionizes to the reactive ylide. The resulting carbanion is stabilized by delocalization of electrons into the carboxyl presumably with the assistance of a one or more positively charged enzyme residues in the vicinity of the carboxyl that then attacks a pyruvate molecule. The $\mathrm{pK}$ for the general acid is abou1 8.4-8.9. The general acid group is observed in all of the same pll rate profiles specified above for the general base, as well as the $\mathrm{pK}_{\mathrm{i} \text { - - -remmpyruate }}$ profiles. Since the same $\mathrm{pK}$ values are observed in the $\mathrm{pK}_{\mathrm{i} \text {--momopyruwate }}$ and $\mathrm{V} / \mathrm{K}$ pll prolile, both enzyme groups must be in their optimal protonation state for eflicient binding of reactants. The general acid group is likely a neutral or acidic residue, since it would be repulsive to the oxygen of pyruvate if it were anionic. As a neutral acidic residue there is also the possibility of hydrogen bonding to the carbonyl of pyruvate. $A 1$ the release of $\mathrm{CO}_{2}$, the lirst reaction, both the general base and general acid groups might be in a protonation state opposite to that in which they started when pyruvate was bound.

Acknowledgments. This work was supported by the Korea Science and Engineering Foundation (R0I-200000137).

\section{References}

1. Limbarger. H. Amti. Rev Biochent 1978, +7.533.

2. Duggleby. R.; Pang. S. J. Biochem. Mol. Biol. 2000. 33.1.

3. Chang. Y.: Weng. A.: Cronen. J. J. Biol. Chem. 1993. 268. 3911.

4. Mucheroux. P.: Schonbrunn. E.: Svergun. D.: Volkov. V.: Koch. M.: Burnemann. S.: Thomeley. R. Biochem. J. 1998. 335. 3911.

5. Gollop. N.: Damri. B.: Barak. 7.: Chipman, D. M. Biochenistry 
1989. 28.6310.

6. Lee. B.: Choi. J.: Yoom. M. Bull. Konem Chem. Soc. 2002. 16. 765 .

7. Pang. S.: Guddat. J .: Duggleby: R. Acta C'rystalog. Sect. D 2001. 57. 1.321 .

8. Pang. S.: Duggleby: R.: Guddat, I. J. . fol. Biol. 2002, 317, 249

9. Chang. S.: Kang. M.: Choi. J.: Namgoong. S. Biochem. Biophys. Rus. Commmin. 1997. 234. 549.

10. Weslerteld. W. J. Biol. Chem. 1945. 161.495.

II. Oh, K.: Park. Г.: Yoon, M: I Jan, T: Choi, J. Biochem. Biophys. Re.s. Commm. 2001, 292.1237.
12. Cleland. W. Hothods Enzomol. 1979.63. 103.

13. Cleland. W. Hothods Enzomot 1982. 87.390 .

14. Cleland. W. Ath Enzzmol. Kolat. Aneas Hol. Biot. 1977. 45. 273.

15. Ibdah, M.: Bar-Ilan. A.: I ivnah. O: Schloss. I.: Barak, 7.: Chipman, D. Biochemistry 1996, 35. 1(1282.

16. Bar-Ilan. A.: Balan. V: Tillmam. K.: Golbik. R.: Vyamensky. M.: Hubner. (ì.: Barak. Z.: Chipman. D. Biochemistry 2001. fo. 11946.

17. Yoon, T.: Chung. S.: Chang. S.: Yoot. M.: I Iahtı. T.: Choi, I. Biochem. Biophys. Res. Commi 2002, 293,433 